\title{
sciendo
}

\section{Big data and AI: a potential solution to end the conundrum of too big to fail financial institutions?}

\author{
Gabriel Razvan MITRACHE \\ Bucharest University of Economic Studies, Bucharest, Romania \\ gabriel.mitrache@gmail.com
}

\begin{abstract}
Disclaimer
The views expressed in this paper are those of the author in his personal capacity. The opinions and assessments herein presented are not and should not be related to the views of the author's

employer. The author's employer is not liable in any way for the present paper and did not contribute to it in any way.
\end{abstract}

\begin{abstract}
The "too big to fail" institutions are a widespread concern, especially in the financial world. Their failure can create severe economic downturns and social turmoil. In past bank failures, governments intervened with public funds to save such institutions from collapse to avoid economic downturns. Since, measures have been put in place to prevent bank failures and limit the utilisation of public funds. However, failures cannot be prevented and risks of affecting the economy are always present in the case of too big to fail institutions. This article explores the possibilities offered by recent advancements in the fields of Big Data and Artificial Intelligence, widely implemented by the financial institutions themselves, as tools to be used by authorities in ending the too big to fail conundrum. The adequate implementation of these technological capabilities will contribute to the areas already targeted by governments - reducing the probability of failure and providing tools to limit negative externalities and spillover effects - and will also introduce a new capability that could address the too big to fail matter. Since financial institutions are, in their essence, data hubs, now in a digitalised format, the possibilities to automate tasks and provide insight for decisions should address the issue. The actual transfer of assets and liabilities to institutions that can carry on the activity, currently need years to be handle:. Big Data and Artificial Intelligence technologies could make such operations a matter of hours or days.
\end{abstract}

Keywords: too big to fail; big data; artificial intelligence; banking resolution; banking supervision; ResTech; regulation.

\section{Introduction}

This is an opinion paper based on a literature review where we explore the advancements of big data and Artificial Intelligence in the banking industry and how these tools and capabilities could be used to address the "too big to fail" institutions.

Big Data and Artificial Intelligence have emerged prominently in the past ten to twenty years, in various industries and for different applications.

One of the industries frequently indicated as benefiting from these technologies is the financial sector. There, the so-called fintech companies managed to provide serious competition to market incumbents.

One of the issues of the financial sector is linked to the potential negative effect that the failure of the main constituents can have on the wider economy. The failure of a large bank can trigger wide economic problems and spillover effects on other financial institutions. Government and authorities have been trying to prevent bank failures and to limit the externalities in case of failure. In the 2008 financial crisis, as well as in previous financil crisis, governments have 
intervened with public money to save failing institutions: the bail-out and the too big to fail institutions.

Since 2008, governments and authorities focus on how to limit bail-outs. While progress has been achieved, it relies mainly on classical, pre-existing tools.

The author questions if the advancements made in big data and artificial intelligence fields, widely adopted in the financial industry by market participants, could be also adopted by authorities to address the too big to fail institutions and limit the bail-out even further (or eliminate them).

In this article, we will explore what is Big Data and what is Artificial Intelligence, what is a too big to fail institution and why this is a problem for the economy. In the final part, we will propose tools based on Big Data and Artificial Intelligence that could be deployed by supervision and resolution authorities.

\section{About Big Data and Artificial intelligence}

The widely accepted and used definition for "big data" is the one introduced by industry analyst Doug Laney (Laney, 2018) in 2001: "Big data is high-volume, high-velocity and/or high-variety information assets that demand cost-effective, innovative forms of information processing that enable enhanced insight, decision making, and process automation."

Some of the leading international companies dealing with software and date agree on this definition and provide further clarifications and guidance on this topic: Oracle (Oracle, 2021), SAS (SAS, 2021). Online dictionaries and encyclopaedia agree and follow the same approach: Wikipedia (Wikpedia, 2021), Investopedia (Investopedia, 2021).

In colloquial terms, we can paraphrase the definition of "big data" along four different dimensions:

Data refers to information. It is not restricted to figures/numbers and it does not have any particular constraints. Pictures, text, audio or video files are part of the data concept.

To be considered "big", the data volume has to be high. While no boundary is given, intuition says we are talking about at least thousands of data points and hundreds of thousands of records. In any case, "big data" would refer to a data volume that could be problematic to be stored and processed in a regular spreadsheet software.

Further, the information is also incoming at a high speed and/or it is of a high variety (and/or it changes its type while also being under collection) to meet the definition of Big Data.

Lastly, the Big Data definition indicates that receivers of "big data" need to adapt their receiving capabilities and management competences so that insights can be derived and decisions can be made based on this data collection and analysis process.

It is not difficult to see how, today, a financial institution (a bank, for example) could be part of the "big data" movement: hundreds or thousands of customers making operations on a daily basis. Each operation described at least by its amount, type (payment, deposit, cash withdrawal etc.), product used (card, cheque, on-line channel), and counterparty. All this without going into the details that are needed for the underlying IT systems for such operations to be performed (IBAN/RIB, authentication and security clearances etc.).

From Britannica (Copeland, n.d.) we learn the definition of Artificial intelligence (AI). It is the capability of a machine to perform tasks commonly associated with intelligent beings, such as finding patterns or meaning, providing generlasations or learning from given examples. A workshop held in 1956 - Dartmouth Summer Research Project on Artificial Intelligence - is widely considered ( (Solomonoff, 1985), (Moor, 2006), (Kline, 2010) ) as the event that established the field of artificial intelligence. 
A practical definition is offered by Investopedia (Investopedia, 2021) by indicating that an ideal characteristic of artificial intelligence is its ability to rationalize and take actions that have the best chance of achieving a specific goal. For more information on AI, definition, subsets, applications etc., the reader might explore Kok's book - Artificial Intelligence: Encyclopedia of Life Support Systems (Kok, 2009).

What is a "too big to fail" institution

The Curse of Bigness (Brandeis, 1965) constitutes the introduction of the concept relating to the issue of large institutions that are so big that their destiny could lvery likely influence the evolution of the underlying economy. Brandeis' book - "Other People's Money and How the Bankers Use It" - is also considered a milestone in the creation of the Federal Reserve System and antitrust laws. (Dash, 2009).

The popularisation of the term "too big to fail" (TBTF) is attributed to U.S Congressman McKinney in a hearing discussing FDIC intervention linked to the failure of the Continental Illinois in 1984. (Federal Deposit Insurance Corporation (FDIC), 1997) (Haltom, 2013). More information on the history of the "too big to fail" topic and related US bank failures can be retrieved in an article published by FED Cleveland (Nurisso, 2017).

Stern and Feldman articulate the key issue of the too big to fail topic: "Determining the appropriate policy response to an important failing bank has long been a vexing public policy issue. The failure of a large banking organization is seen as posing significant risks to other financial institutions, to the financial system as a whole [...]" (Stern, 2004). In the subsequent parts, we will explain why TBTF poses moral hazard: rewarding least performing economic players over the fear of a pronounced generalised economic downturn by spending public money.

\section{Why is TBTF a conundrum?}

The too big to fail institutions are a puzzle at the border of politics and economy. In a free economy, economic agents should exit the market as soon as they fail. Failure of an economic agent is linked to not being able to repay its debts, be they short or long term. Regardless of the causes of failure, national laws have insolvency proceedings for failing companies.

A few notable exceptions to this quick exit from the market exist: strategic industries (where the government will not abandon production or research even if there are no customers) and too big to fail companies.

Too big to fail companies can pertain to any industry/economic sector. In the past, governmental interventions have been seen, for example, targeting car or airplane manufacturers with large numbers of employees. Such intervention measures aim to mitigate the risk of potential massive unemployment, among others, that would create social unrest and could further trigger or accentuate the economic downturn. A particular case of TBTF are financial institutions and more precisely banks.

When a large bank fails, governments are at a cross roads between the implications of letting the failed entity exit the market and intervening to save it. This is because, on one hand, the externalities of a large failed bank can be devastating for the economy, and on the other hand saving a failed entity equals rewarding the least performing agent.

Banks are at the pinnacle of any economy. Do they not only intermediate the transactions (payments, cards, various credit or debit instruments) but also part of their sources come from private persons and other economic agents. Rendering these funds unavailable would create turmoil and financial issues for a large number of other entities, therefore spreading their difficulties to the 
wider ecosystem. The larger the bank, the more clients it has and therefore the more profound and of a larger radius the negatives consequences are.

Saving a failing bank to avoid the potential negative outcomes on the economy poses two difficulties. The main one relates to the moral hazard of rewarding a non-performing entity. It would be expected to reward the most performing entities but in this case, the ones that can no longer meet their debts would get a reward. In turn, this would encourage other entities to take too many risks (as higher risks are linked to higher returns, the ultimate goal of a private enterprise) and lead to increased probability of a subsequent failure. The second issue is the challenge of setting a clear boundary beyond which a bank becomes a TBTF institution. It can be argued that since there is a lot of uncertainty on externalities in case of bank failure and there are no clear, objective, guidelines of where a failure could provide spill over effects or not, governments are inclined to intervene to save failed institutions (Mitrache, 2018).

The government intervention to save failing banks was conducted via bail-out: public money introduced to cover the bank's losses. The UK National Audit Office indicated that in 2010 the scale of the support provided to the banks had fallen from its peak of $£ 955$ billion to $£ 512$ billion as at 1 December 2010 (National Audit Office, 2010). An analysis for the US indicates that the total direct cost of bailouts on a fair value basis is about $\$ 498$ billion (or 3.5\% of 2009 GDP) (Lucas, 2019).

\section{Big Data and Artificial intelligence in the financial world}

Banking can be traced back to the Roman Empire, with the first records of a bank from 1401 (Taula de la Ciutat, in Barcelona) and the oldest still operating bank being Banca Monte dei Paschi di Siena (operating since 1472).

For a bank to function it needs to keep accurate records of its counterparties: to whom it owes money and to whom it lent money.

Starting in the 1920s, the first tools, such as accounting machines and punch card machines, have been introduced to help automate calculations and other task in banks (BNP Paribas , 2021).

In 1950, Bank of America introduced the world's first computer used in banking - ERMA - Electronic Recording Method of Accounting (Bank of America , 2021).

With the expansion of ARPANET (the predecessor of Internet), in 1981, and with the introduction in 1982 of the Internet Protocol Suite, a new era was opened for digitalisation and exchange of information.

The transition to digital collection, storage and management of information has been growing at an accelerated pace since. Figure 1 indicates in a visual way the accelerated development of the digital data collection and management, also describing the 2000s as the digital age start. 


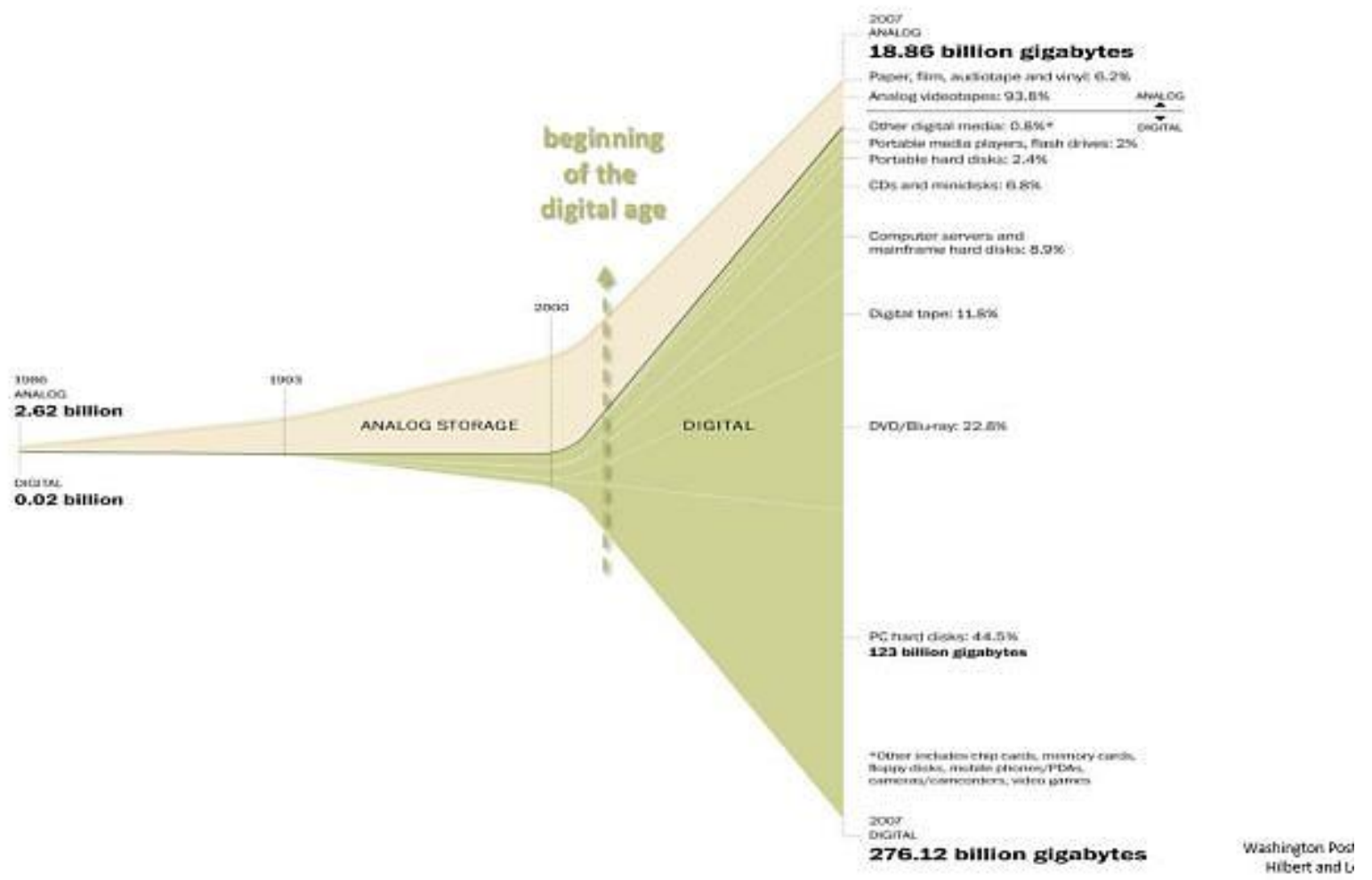

PICBE |

Figure 1. Estimation of the world's technological capacity to store, communicate, and compute information, tracking 60 analogue and digital technologies during the period from 1986 to 2007

Source: http://www.martinhilbert.net/worldinfocapacity.html/.

From the beginning of 2000s, "the penetration of the internet and mobile phones has produced a profound transformation of the habits and preferences of consumers, who are becoming increasingly used to interacting via digital media to share information about themselves, conduct their dealings with the authorities, shop online or access new services." (Cuesta, Ruesta, Tuesta, \& Urbiola, 2015)

We are now 20 years in the "digital age". Financial institutions have deployed and incorporated various practices linked to Big Data and AI. Such deployments were orientated for their own managerial benefit and responding to legal requirements (such as accounting standards, disclosure obligations or supervisory requirements). More recently, a new breed of financial players has taken a share of the market, challenging incumbents: fintechs.

Fintech (the European Banking Authority's definition of Fintech can be retrieved from the bybliografy) companies base their operations on big data and AI as a driver of their business model. Relying on automation and predictions they can quickly adapt their services to customer requirements, automate processes reducing costs. The first fintech as we know today is considered to have been launched in 2008 (Arner, 2016).

Figure 3 depicts a scale of the technological advancements in he financial industry. For more than 600 years written records were made and only in the last 100 years automation started, with fintechs emerging less than 15 years ago. 


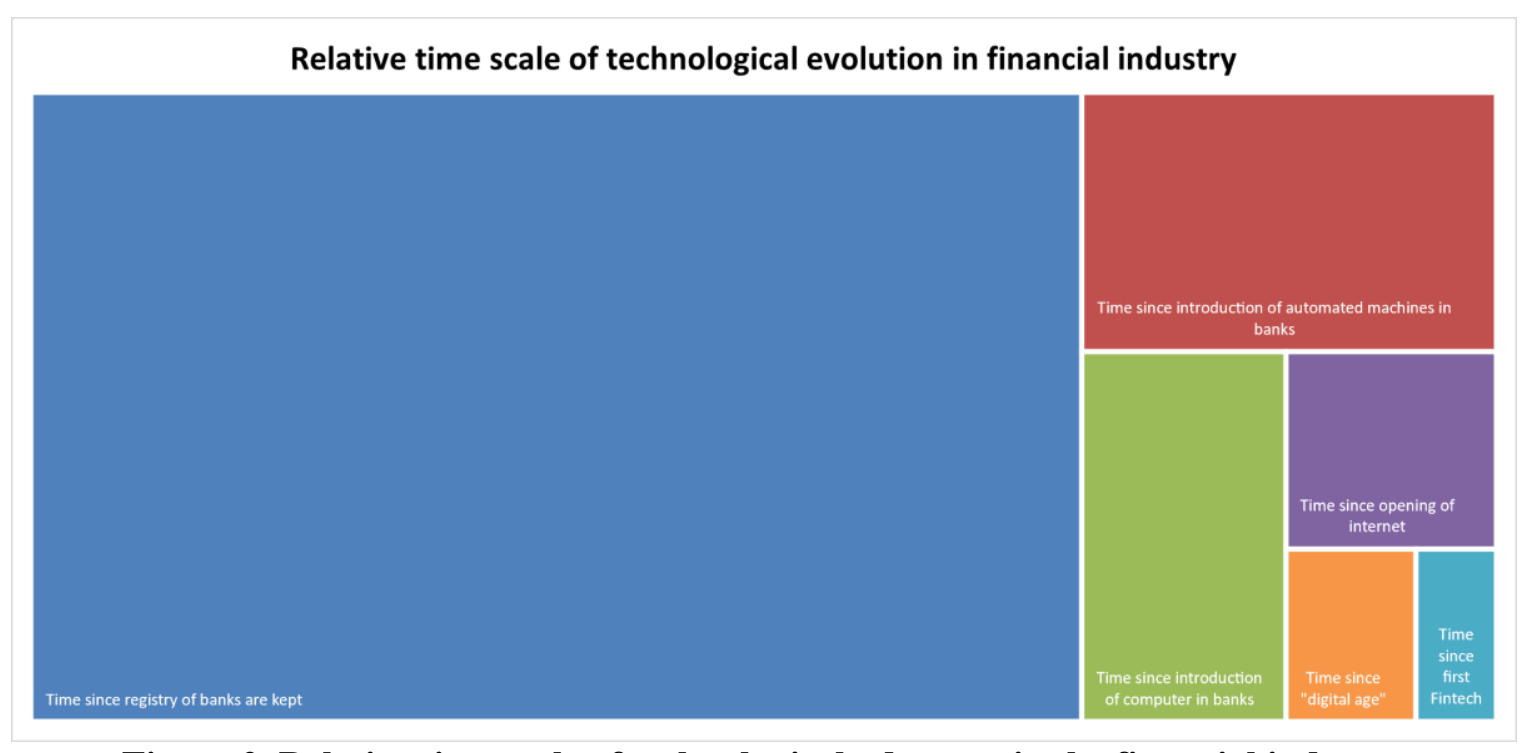

PICBE |

Figure 2. Relative time scale of technological advances in the financial industry

Source: Author's own creation based on text and dates presented in this paper.

We believe that supervision and resolution authorities can greatly benefit from recent developments in the Big Data and AI technologies and capabilities. Such utilisations could put an end to TBTF conundrum. Insights and predictions and automation could be leveraged to identify early risks, provide better decision capabilities and allow for swift application of resolution tools and powers. The preparation of the underlying IT frame to accommodate Big Data and AI would also create the premises for resolving failing banks in an efficient and timely manner, without great externalities.

\section{How could Big Data and AI be the solution for TBTF institutions?}

Ultimately, financial institutions are data centres: how much they owe, to whom, at what rate, who owes them, at what maturity etc. Historic records are also important and used in netting arrangement, for example. This is why fintech players managed to challenge on a short time period the large incumbents. They leveraged big data and AI capabilities for innovative solutions such as: immediate transfers of money from one country to another (at negligible or very low costs), screening for potential fraudulent transactions (out of pattern), payment security (for example only if the card is near the mobile phone) etc. More importantly, such fintechs are able to meet regulatory requirements based on advanced analytics rendered by AI.

The concept of ResTech is new. Loiacono et al. (Loiacono, Mazzullo, \& Rulli, 2020) argue in their paper that ResTech could be part of the solution to innovative technologies for crisis resolution.

The applications envisaged in this paper require only weak AI deployments. Weak AI (or artificial narrow intelligence) has a narrow range of possibilities, as opposed to a strong or deep AI (Artificial General Intelligence) which is on par with humans or to artificial super intelligence which is beyond human capabilities (and this point theoretical).

We can see a plethora of applications where supervision and resolution authorities could take advantage of big data and AI technologies to reduce even further potential bank failure and manage a bank failure without making recourse to bailouts (government intervention). 
A weak AI can be deployed for operations that can be automated or benefit from guidance as they repetitions or where the output is expected to be a prediction or an insight (such as discovery of patterns or categories). It is not difficult to observe that various business models and activities are designed to make underlying component tasks repeatable and predictable: standardised process that do not require human creativity are the most efficient at scale. Financial institutions offer standardise products and services. Supervisors collect standardise reports and produce standardised findings and insights. Bank of America indicates that automatic processing was the reason fro introducing the first computer in this workforce: "[In the 1950s,] Bank of America was the largest bank in California and processed more checks than any other bank in the world. While popular and convenient, checks presented a serious problem in the bank's back offices - it took a huge Bank of America workforce and countless hours to process millions of checks per month and more than a billion per year. All checks had to be cleared by hand and banks were closing by 2:00 p.m. to process them all. [...] By 1954, the first computer for business use was delivered. [...] Data was fed into this factory-sized computer through magnetic tapes, which processed at a rate of 12,000 numbers or letters per second. [...] It processed checks faster and more efficiently than ever before, approximately 33,000 accounts in the time it would take an average bookkeeper to do 245." (Bank of America , 2021).

Some applications are probably used by supervision and resolution authority, but not necessarily employing AI tools. In the following paragraphs we will explore some easy to deploy machine learning (subcategory of AI) algorithms.

One of the products of the 2008 financial crisis was the creation of the EBA stress test. "The aim of such tests is to assess the resilience of financial institutions to adverse market developments, as well as to contribute to the overall assessment of systemic risk in the EU financial system. The EBA's EU-wide stress tests are conducted in a bottom-up fashion, using consistent methodologies, scenarios and key assumptions developed in cooperation with the ESRB, the European Central Bank (ECB) and the European Commission (EC)." (EBA, 2021). This framework, revolutionary at its inception, has two limitations: it assesses institutions robustness in solitude (i.e. spill over risks are not traced) and a group of experts projects a stress scenario (i.e. institutions are tested against a given scenario). However, an AI approach would enable the identification, on a continuous basis, of scenarios where the financial system is the most exposed (for example, the top 5 scenarios with the largest loss given default). This set-up will be designed as a reverse stress-test where machines could identify on a continuous basis what are the major risks in a given geographic region, including contagion effects. Concretely, the system, leveraging a central database could at any moment identify the most catastrophic potential scenarios system wide and could point to what should be remedied.

A random forest approach could be used by resolution authorities to test the approach that is more likely to result in the most efficient action. Resolution authorities can use four resolution tools in various combinations (bail-in, sale of business, bridge banks and sale of assets) in order to maximise a number of legally required objectives (such as protection of depositors and assets, ensuring continuity of critical functions etc.). While the underlying approach can me modelled in a maximisation function given constraints, the addition of a random forest, that is a specific type of aglrithm that develops based on decision trees, would provide further insights for the decisions to be taken with that model. The process runs by generating multiple decision trees using variations of the original dataset and arbitrarily picking a subset of variables for every node of the decision tree. By relying on a "majority wins" model, it reduces the risk of error from an individual tree (Donges, 2020). 
To continue the previous example, since not all combinations of resolution tools are equally desirable given specific circumstances of the moment, a specific type of random forest algorithm could be used - XGBoost. This will allow for a customisation of the best strategy based on the specific circumstances of the moment. Specific penalisation of trees could be further applied to simulate the various constraints the intervening resolution authority has in its legal framework. (Shin, 2021).

Unsupervised learning algorithms can be deployed for a number of assessments that would assist a human beneficiary (e.g. an expert in a supervision authority). For example, given a collection of regulatory reports from all institutions in a remit, the algorithm could identify outlining values or contrast patterns. A database could be used to teach the model what are malign or benign outliers or patterns, based for example or previous human detection of money laundering or fraud or human error in bookkeeping. The human supervision could, instead of going to a lineby-line audit of the reports, identify if there are any prominent issues. This is the exact same example given by Bank of America for its decision to introduce computers in its activity.

In a different approach, institutions could be categorised based on various criteria. The algorithms would be able to find resemblances and patterns and attribute labels. Such categories would go beyond what a human could identify by herself, such small, medium and large institutions. The AI could dynamically detect what are the most important variables to retain for the classification and further use them for predictions. A similar approach is used by banks that employ internal models to estimate their own funds requirements.

Further, if human experts offer feedback to the algorithms, the unsupervised algorithm would become a supervised learning one. Over time, it will learn to identify problematic transactions (anti money laundering issues, for example). In the labelling example above, the human supervisor could agree to keep only certain labels that provide interest and discard the others. In this instance, the AI would understand what is valuable and provide new metrics or labels, while retaining the ones saved by the human expert. This process would be no much different that providing suggestions based on purchases made online on recommendation for movies or music based on previously watched/listened ones.

Based on collected data on failed banks, where a human would label the failing triggers, AI algorithms could reconstruct the path to failure. Further, the algorithms applied to ongoing institutions would be able to detect and anticipate potential similar paths to failure as the ones in the past.

Generative adversarial networks (GAN) could be used in a number of instances. For example, the stress test that we mentioned before could be replaced at institution level by a GAN: a network would try to identify all the institution's failure positions. In a different application, a resolution authority could deploy the financial position of an institution and benefit from a view of the possible outcomes in case of failures. It would be possible to test various intervention measures against a wide range of market movements to determine the likely best approach for each scenario.

Microsoft is transforming itself into an AI driven company. DelBene, the person in charge of this process explained: "We leverage AI to know when things are starting to behave in unexpected ways. The best we could do in the past was to react as fast as possible. Now we can pre-empt things, from bad contracts to cyber breaches." (Iansiti \& Lakhani, 2020). We believe, through the examples given above, this is what the financial supervisors could enhance their game.

Finally, the main achievement would be after such big data and AI technologies would be deployed, as they would trigger a higher level of data standardisation and orientation for a more atomic and structured data set. The implementation of standardised data sets in the final institutions 
(as opposed to currently only standardised reports) would trigger the main benefit for tackling to big to fail companies. Now, the main hurdles in dealing with a fail bank relate to the time need to perform an intervention: authorities need years to perform an accounting valuation of the failing institution (such valuation being the one thing indicated to the level of losses and attesting the failure). Further, in order to transfer the failed banks assets and liabilities (to a purchaser or a bridge bank), more months (or years) are necessary: the data bases are not compatible, the IT hardware and software are rarely compatible. Transposing data from one bank's database to another is a incredible demanding task that also encompasses high risks. Now imagine that banks run a core of standardised data sets: the software for valuation could be deployed very quickly connected (plug and play) but also it would increase transparency: each party would now in advance the dataset structure so it could create its own valuation model and rely on its own knowledge. Further, the transfer of assets and loans would only take days, as the database structures would be compatible. Dealing with a bank failure would only take days and would leverage increased levels of confidence in the market.

\section{Results and discussions}

Big data and AI entered the financial institutions as a response to competitive pressure, in itself a driver for advances and research in this field. However, each institutions' database and approach might be different, also relying on similar but not the same data points (descriptors of monetary transactions cannot be under a too much creative design).

A requirement to standardised the datasets would not only facilitate the data transfer in a quick and efficient way in case of a bank failure (quick and reliable valuation and transfer to a purchaser) but would also help decrease the risk of bank failure by anticipating possible downturn scenarios.

A number of potential applications where supervision and resolution authorities would work on big data structures by employing AI algorithms have been presented, jointly contributing to the various pillars of an enhanced financial supervision: decreasing probability of default, anticipation of potential defaults, and limitation of losses given default though swift and wellinformed decision.

Some of the applications can be quickly deployed on existing harmonised regulatory and financial reporting standards. Some approaches would require further work to define the needed data points and determine more harmonisation on how institutions manage their datasets.

To arrive to a steady state of day-to-day utilisation of big data and AI a number of four components are necessary (Iansiti \& Lakhani, Competing in the Age of AI, 2020):

i. Data gathering process - automated as much as possible, to collect and integrate data in a sustainable and scalable way;

ii. The algorithms - that provide insights based on the collected data;

iii. A testing platform - where outputs from the algorithms can be measured and evaluated;

iv. The infrastructure - the platform that puts the first three points together and allows it as a system to connect with users.

Now is a time for change, where the architecture should be lead by designs that leverage integration of data and the adoption of a unified and consistent data code. 


\section{Conclusion}

Given that financial institutions rely on records of data for their business (record of the monetary transactions), and given the high trend for digitalisation seen in the past 20 years, it is only a matter of time until AI tools will be employed by supervisors for more complex and wide applications that would enhance supervision and provide probably fail proof safety for the system.

While discussions have started by different authorities in this regard, practical applications remain scarce or not available to the public. A concentrated effort could be needed from authorities in order to provide benchmarks and standards for what a bank database should be (as opposed to standardised reports) that financial institutions should need to implement to be licensed, for example. Using a standardised data set, while having an implementation cost (regulatory cost) it would create scale saving in the long term as more institutions will have easier access to advanced software and, as we have shown in this paper, the need to intervene to save a failed institution will be a matter of deploying certain AI routines that will provide transparency, efficiency and clarity for the market. Ultimately, the market confidence will benefit and very likely help put an end to what is the too big to fail type of institutions in the financial world.

\section{References}

Arner, D.W. (2016, June). FinTech: Evolution and Regulation. Retrieved from law.unimelb. edu.au: https://law.unimelb.edu.au/data/assets/pdf_file/0011/1978256/D-Arner-FinTech -Evolution-Melbourne-June-2016.pdf.

Bank of America. (2021, 2 21). Bank of America . Retrieved from https://about.bankofamerica .com/: https://about.bankofamerica.com/en-us/our-story/bank-of-america-revolutionizesindustry.html\#fbid=eUf9ORFuShT.

BNP Paribas. (2021, 2 21). BNP Paribas . Retrieved from https://history.bnpparibas/: https:// history.bnpparibas/dossier/a-brief-history-of-it-in-the-banking-industry/.

Brandeis, L. D. (1965). Curse of Bigness. Kennikat Press.

Copeland, B. (n.d.). Artificial intelligence. Retrieved from Encyclopedia Britannica: https:// www.britannica.com/technology/artificial-intelligence. Accessed 22 February 2021.

Cuesta, C., Ruesta, M., Tuesta, D., \& Urbiola, P. (2015, 7 16). The digitaltransformation of the banking industry. BBVA Research.

Dash, E. (2009, 620$)$. If It's Too Big to Fail, Is It Too Big to Exist? The New Yors Times.

Donges, N. (2020, 9 3). A complete guide to the random forest algorithm. Retrieved from https://builtin.com/: https://builtin.com/data-science/random-forest-algorithm.

EBA. (2021, 2 21). EBA. Retrieved from https://www.eba.europa.eu/: https://www.eba.europa.eu/ risk-analysis-and-data/eu-wide-stress-testing.

EBA. (n.d.). GLOSSARY FOR FINANCIAL INNOVATION. Retrieved from www.eba.europa.eu: https://www.eba.europa.eu/sites/default/documents/files/documents/10180/2270404/7203 6f35-beac-4d44-acf1-2875c12b709e/Glossary\%20for\%20Financial\%20Innovation.pdf? retry $=1$.

Federal Deposit Insurance Corporation (FDIC). (1997). An Examination of the Banking Crises of the 1980s and Early 1990s. Washington, DC: FDIC.

Haltom, R. (2013, 11 22). Federal Reserve History. Retrieved from https://www.federalreserve history.org/: https://www.federalreservehistory.org/essays/failure-of-continental-illinois.

Iansiti, M., \& Lakhani, K. R. (2020, January-February). Competing in the Age of AI. Harward Business Review, 61-67. 
Iansiti, M., \& Lakhani, K. R. (2020). Competing in the Age of AI: Strategy and Leadership When Algorithms and Networks Run the World. Boston, MA: Harvard Business School Publishing Corporation.

Investopedia. (2021, 1 30). Investopedia. Retrieved from Investopedia.com: https://www .investopedia.com/terms/b/big-data.asp.

Investopedia. (2021, 2 7). Investopedia. Retrieved from https://www.investopedia.com/: https://www.investopedia.com/terms/a/artificial-intelligence-ai.asp.

Kline, R. R. (2010). Cybernetics, Automata Studies and the Dartmouth Conference on Artificial Intelligence. IEEE Annals of the History of Computing, 5-16.

Kok, J. N. (2009). Artificial Intelligence: Encyclopedia of Life Support Systems. Oxford, U.K.: Eolss Publishers.

Laney, D. (2018, 1). https://www.kdnuggets.com/2018/01/exclusive-interview-doug-laney-bigdata-infonomics.html. (G. Piatetsky, Interviewer).

Loiacono, G., Mazzullo, A., \& Rulli, E. (2020). ResTech: innovative technologies for crisis resolution. SSRN Electronic Journal.

Lucas, D. (2019). Measuring the Cost of Bailouts.

Mitrache, G. (2018). A game of bank resolution. Theoretical and Applied Economics, 209-217 .

Moor, J. (2006). The Dartmouth College Artificial Intelligence Conference: The Next Fifty years. AI Magazine, 87-91. Dartmouth: American Association for Artificial Intelligence.

National Audit Office. (2010, 12 15). Maintaining the financial stability of UK banks: Update on the support schemes. Retrieved from National Audit Office: https://www.nao.org.uk/report/ maintaining-the-financial-stability-of-uk-banks-update-on-the-support-schemes/.

Nurisso, G. (2017, 10 18). Federal Reserve Bank of Cleveland. Retrieved from https://www. clevelandfed.org: https://www.clevelandfed.org/newsroom-and-events/publications/econo mic-commentary/2017-economic-commentaries/ec-201717-origins-of-too-big-to-fail.aspx \#D2.

Oracle. (2021, 1 30). Oracle.com. Retrieved from Oracle: https://www.oracle.com/uk/bigdata/what-is-big-data/.

SAS. (2021, 1 30). SAS. Retrieved from SAS.com: https://www.sas.com/en_gb/insights/bigdata/what-is-big-data.html.

Shin, T. (2021, 1). All Machine Learning Algorithms You Should Know in 2021. Retrieved from https://www.kdnuggets.com: https://www.kdnuggets.com/2021/01/machine-learning-algo rithms-2021.html.

Solomonoff, R. (1985). The Time Scale of Artificial Intelligence. Reflections on Social Effects, Human Systems Management, vol5, 149-153.

Stern, G. H. (2004). Too Big to Fail: The Hazards of Bank Bailouts . Brookings Institution Press.

Wikipedia. (2021, 2 7). Wikipedia. Retrieved from https://en.wikipedia.org/: https://en.wikipedia .org/wiki/Artificial_intelligence.

Wikpedia. (2021, 1 30). Wikipedia. Retrieved from Wikipedia.com: https://en.wikipedia.org/ wiki/Big_data. 